\title{
IDŐJÁRÁS
}

Quarterly Journal of the Hungarian Meteorological Service

Vol. 124, No. 4, October-December, 2020, pp. 483-497

\section{Foehn classification and climatology in Sofia for 1975-2014}

\author{
Krasimir Stoev $^{1,2 *}$ and Guergana Guerova ${ }^{2}$ \\ ${ }^{1}$ National Institute of Meteorology and Hydrology, \\ 66 Tsarigradsko shose Blvd., BG-1784 Sofia, Bulgaria \\ ${ }^{2}$ Sofia University "St. Kliment Ohridski" \\ Department of Meteorology and Geophysics \\ 5 James Bourchier blvd., BG-1164 Sofia, Bulgaria \\ *Corresponding author Email:krasimir.stoev@gmail.com \\ (Manuscript received in final form January 22, 2020)
}

\begin{abstract}
Foehn is a warm, dry, and downslope wind blowing in the lee side of a mountain range. It is a well known example of a local atmospheric circulation. The foehn wind is also an extreme weather event, and its forecasting is an important task for the short-range weather forecaster. The foehn in Bulgaria is observed on the northern slopes of the mountains, as a result of warm air advection from the south and southwest. Its occurrence is highest north of the Vitosha and Balkan mountains. In this study, a synoptic classification of the meteorological conditions leading to foehn in the central meteorological station in Sofia for the period 1975-2014 is made. Foehn climatology is prepared, and in addition, an evaluation of the foehn as an extreme weather event by wind gust is presented. For the period 1975-2014, there were 298 days with foehn in Sofia, which resulted from 220 synoptic cases. A manual foehn classification was developed with four major types. Type I is associated with the Mediterranean cyclone with the highest frequency $-52 \%$ of the foehn days. Foehn climatology gives average annual number of 7.5 foehn days but with a large variance between decades. The lowest annual number of days (4.5) is registered for the 2005-2014 period, and it was associated with the lowest recorded wind gust $(22 \mathrm{~m} / \mathrm{s})$.
\end{abstract}

Key-words: foehn; extreme weather event; foehn climatology; foehn classification 


\section{Introduction}

Foehn is a warm, dry, and downslope wind blowing in the lee side of a mountain range. In Europe, foehn is observed in many Alpine stations in Switzerland, Austria, and Italy. Studying the Altdorf foehn, Gutermann et al. (2012) and Richner and Hachler (2013) conclude that: 1) there is no long-term trend in the foehn frequency for a period of over 150 years, 2) there is considerable year to year variability averaging of 60 foehn observations per year, with a maximum of 114 observations (1872) and a minimum of 27 observations (1955), and 3) the foehn frequency has a pronounced seasonal cycle. Numerical modeling of foehn flows remains a challenge, even for the $1 \mathrm{~km}$ horizontal resolution Numerical Weather Prediction model, currently operated by MeteoSwiss (Willemse and Furger, 2016).

The occurrence of the foehn is related to the development of cyclonic vortices in the presence of an advection of warm and moist air masses from south and southwest. The Mediterranean sea is a well known area where cyclones form, and their influence over the weather and the climate in Bulgaria are discussed by many authors, such as Stanchev (1954), Pisarski (1955a,b), Blagoev (1961), Martinov (1967), Peiter (1975), and Radinovic (1987). In these works, the cyclones are identified and classified on the basis of synoptic analysis. Results for monthly and annual distribution of the cyclones, generated over the Mediterranean during the period 1980-2001, show that the highest cyclones frequency occurs during winter, from December to March (Bocheva et al., 2007). After 1990, the frequency of the cyclogenesis over the Mediterranean was found to be two months shorter than average occuring mainly over the central part of the sea (Marinova et al. 2005).

The first investigations of the Mediterranean cyclone trajectories were made more than 100 years ago, to explain the different climatological conditions in particular regions in Europe (van Bebber, 1891). Later on, the main paths of the Mediterranean cyclones and their seasonal variability are studied by many authors: Pisarski (1955a,b), Popova et al. (1975), Martinov (1983), and Jansa et al. (2001). In almost all studies, 3 main trajectories are mentioned: path I (northwest NW), through Croatia and Hungary; path II (east E), through the Adriatic Sea and the Balkan Peninsula toward the Black Sea; path III (southeast SE then E), through the southern parts of the Balkan Peninsula toward Asia Minor.

In Bulgaria, classical foehn occurs when a Mediterranean cyclone trajectory is NW of Bulgaria (Pisarski 1955a,b). The cyclones on path I, have different frequency through the different years. When they are predominant, winters in Bulgaria are warm (Weather types in Bulgaria, IMH, 1960). Path I, through Croatia and Hungary, is not typical any more (Marinova et al., 2005). Almost all cyclones on path I are formed over the Gulf of Genoa. Then they pass over the Apennines, the Adriatic Sea, the Dinaric Mountains, and the Hungarian 
lowland. In this case, the frontal system of the cyclone is situated northwest of Bulgaria, and the Balkan Peninsula is in the warm sector of the cyclone. These synoptic conditions are most pronounced during the transitional seasons and winter. Most frequently, the upper flow consists of tropical air transported from North Africa over Bulgaria. First, the south wind orographically rises because of the mountains. When the cyclone moves over Hungary, a foehn occurs north of the mountains, and it may lead to a significant increase of temperature. When the cyclone moves NE-E of Hungary, over Bulgaria a cold front passes. Cold air advection is caused by strong NW wind.

The formation of the foehn is connected to the modification of the air flow which is influenced by the orography. The foehn in Bulgaria is observed on the northern slopes of the mountains as a consequence of warm air coming from south (S) and southwest (SW). It occurs most frequently north of the Vitosha (Sofia plain) and the Balkan mountains. Most often wind gusts reach 15-20 m/s during the foehn in Bulgaria, but there are cases when it is observed as a violent gusty wind with speeds up to $25-30 \mathrm{~m} / \mathrm{s}$, causing considerable damage.

The foehn in Sofia usually occurs during the advection of warm and moist air masses from S or SSW. After passing over the Vitosha and Lulin mountains, the air descends to the lee side (Sofia plain), and adiabatically warms and dries. When such wind is present, a cloud wall forms south of the Cherni Vruh peak (2290 m asl.) of Vitosha Mountain. The studies of Hristov and Tanev (1970) for the period 1955-1964 show that there are annually 7-8 days on average with a foehn in Sofia. In 59\% of the observations with foehn there is an increase in the temperature ranging from 5 to $10{ }^{\circ} \mathrm{C}$ in $64 \%$, from 11 to $15{ }^{\circ} \mathrm{C}$ in $34 \%$, and from 16 to $20^{\circ} \mathrm{C}$ only in $2 \%$ of cases. The authors of the studies report a maximum number of days with foehn in February and March, and a minimum from June to October. More than half of the cases are with wind gust below $20 \mathrm{~m} / \mathrm{s}$.

The aim of this study is to make foehn climatology and classification of the synoptic conditions that lead to its occurrence in Sofia plain during the period 1975-2014. To achieve this, a 40-year-long period is analyzed. In Section 2, the data and the method are described. In Section 3, the results are presented. In Section 3.1, classification of the foehn type is made. In Section 3.2, the climatology of the foehn in Sofia is presented. In Section 3.3, the foehn is assessed as a severe weather event. Conclusions are given in Section 4.

\section{Method and data sets}

To determine the days with foehn, observations from the central meteorological station of the National Institute of Meteorology and Hydrology (NIMH) in Sofia for a 40-year-long period is analyzed. Synoptic observations are made every 3 hours at 00, 03, 06, 09, 12, 15, 18, and 21 UTC. Observations are made according to the standards and recommendations of the World Meteorological 
Organization (WMO), namely: 1) wind speed and direction are measured at 10 $\mathrm{m}$ height above ground, and 2) the other meteorological elements are measured in a meteorological station, situated at $2 \mathrm{~m}$ above ground. In this study, the following meteorological elements are analyzed: 1) wind speed and direction, 2) air temperature, including the maximum temperature, 3) relative humidity, and 4) atmospheric pressure at the station level $(595 \mathrm{~m})$.

Foehn is best observed during the morning and evening hours, when the rise of temperature and the fall of the relative humidity are following unusual patterns. Special attention is paid to the increasing speed of the wind, accompanied by the sharp and significant increase of the temperature and sharp and significant drop of the relative air humidity. Hristov and Tanev (1970) analyzed the period 1955-1964 and proposed a quantitative criteria for determination of the occurrence of foehn: 1) appearance of a wind from south $\left(112-247^{\circ}\right)$ and an increase of its speed at least with $\left.5 \mathrm{~m} / \mathrm{s}, 2\right)$ sharp and considerable increase of the temperature $\left(5^{\circ} \mathrm{C}\right.$ or above), and 3$)$ decrease of the relative air humidity with more than $20 \%$ for 3 hours, especially in the observations in the morning and evening. The quantitative foehn criteria proposed by Hristov and Tanev (1970) are used in this study and presented in Fig. 1.

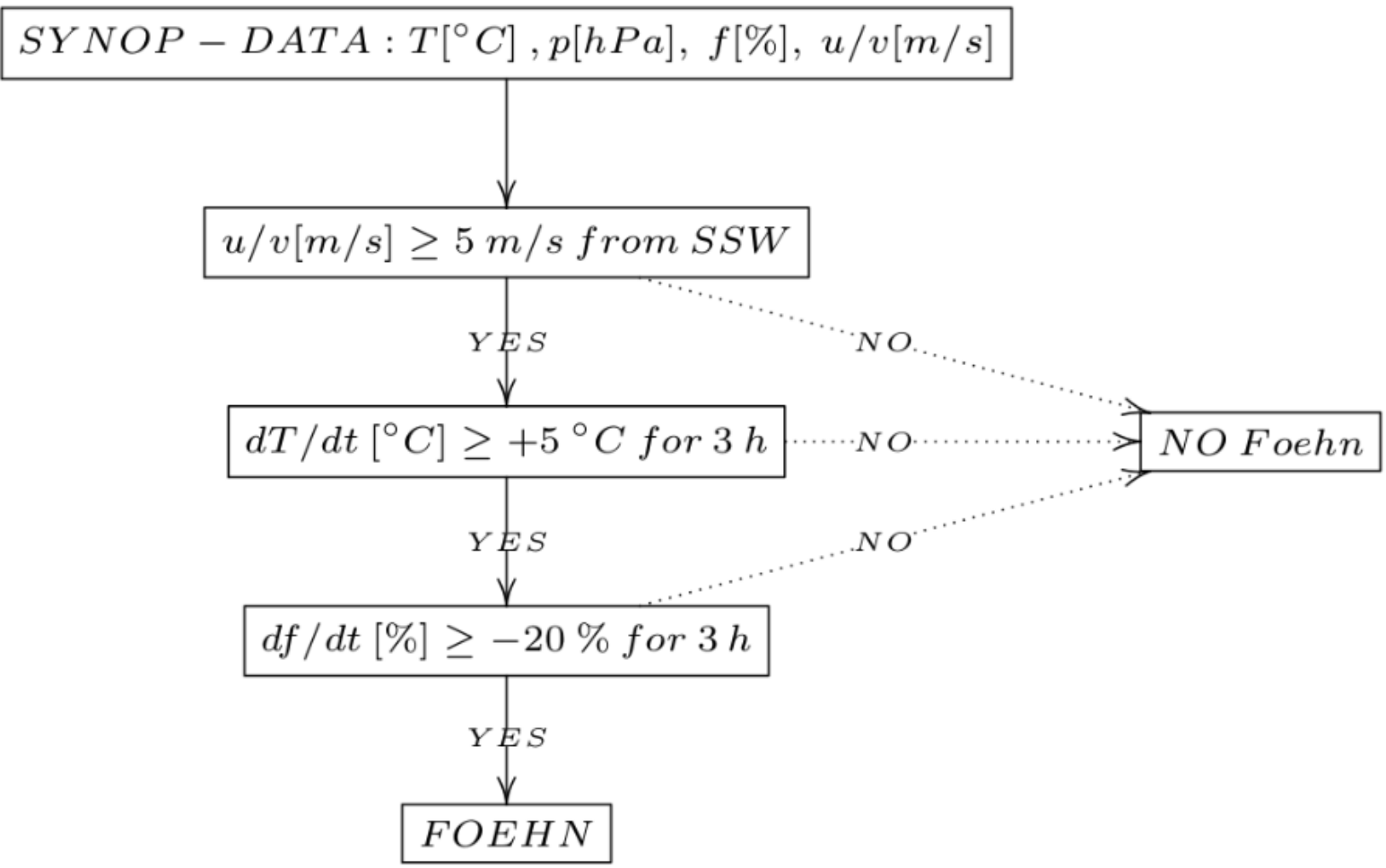

Fig. 1. Schematic presentation of the foehn selection criteria. 
Synoptic conditions are analyzed for a 40-years period from 1975 to 2014 . For the analysis, the reanalysis archive of the National Centres for Environmental Prediction (NCEP, www.wetterzentrale.de/topkarten/fsres.2eur.html) is used. Charts of surface pressure, geopotential height at $500 \mathrm{hPa}$ (AT500), geopotential height and temperature at $850 \mathrm{hPa}$ (AT850), and relative humidity at $700 \mathrm{hPa}$ (AT700) are analyzed. Depending on the atmospheric circulation, a classification is made of the conditions that lead to the appearance of the foehn in the area of the central meteorological station in Sofia. Satellite images from the archive of Dundee University (http://www.sat.dundee.ac.uk/) are used in addition. Satellite data are from a polar orbiting satellite AVHRR in the Visible channel (VIS $0.58-0.68 \mu \mathrm{m}$ ) and infra-red channel (IR, 0.725 and $1.10 \mu \mathrm{m}$ ). For assessment of the foehn as a severe weather phenomenon, the criteria of the European system Meteoalarm is used (http://weather.bg/images/static/Meteoalarm_0.pdf).

\section{Foehn classification and climatology for Sofia}

\subsection{Foehn classification for Sofia}

Classification of synoptic conditions is made manually on the basis of the surface pressure charts from the NCEP reanalysis. For this purpose, the movement of the main synoptic centers and frontal systems is traced, and those causing foehn in the area of Sofia are selected.

\subsubsection{Foehn type I}

In Fig. $2 a$, the cyclone trajectories of type I foehn and the classes Ia, Ib, Ic, Id, and Ie are shown. Class Ia (54 cases) corresponds to the Mediterranean cyclone moving NW of Bulgaria. Foehn class Ib is observed in 13 cases. The cyclone forms over Italy moving through the NW regions of the Balkan Peninsula, west of path Ia (Fig. 2a). Foehn class Ic is observed in 15 cases. In this case the cyclone forms over the southern parts of Italy, moves in E-NE direction, and most often passes close to the west border of Bulgaria. Foehn class Id is observed in 26 cases. During class Id, the cyclone forms over North Italy and passes through the Hungarian plain. Foehn class Ie is observed in 6 cases. During class Ie foehn, the cyclone moves from Italy directly to the north. 


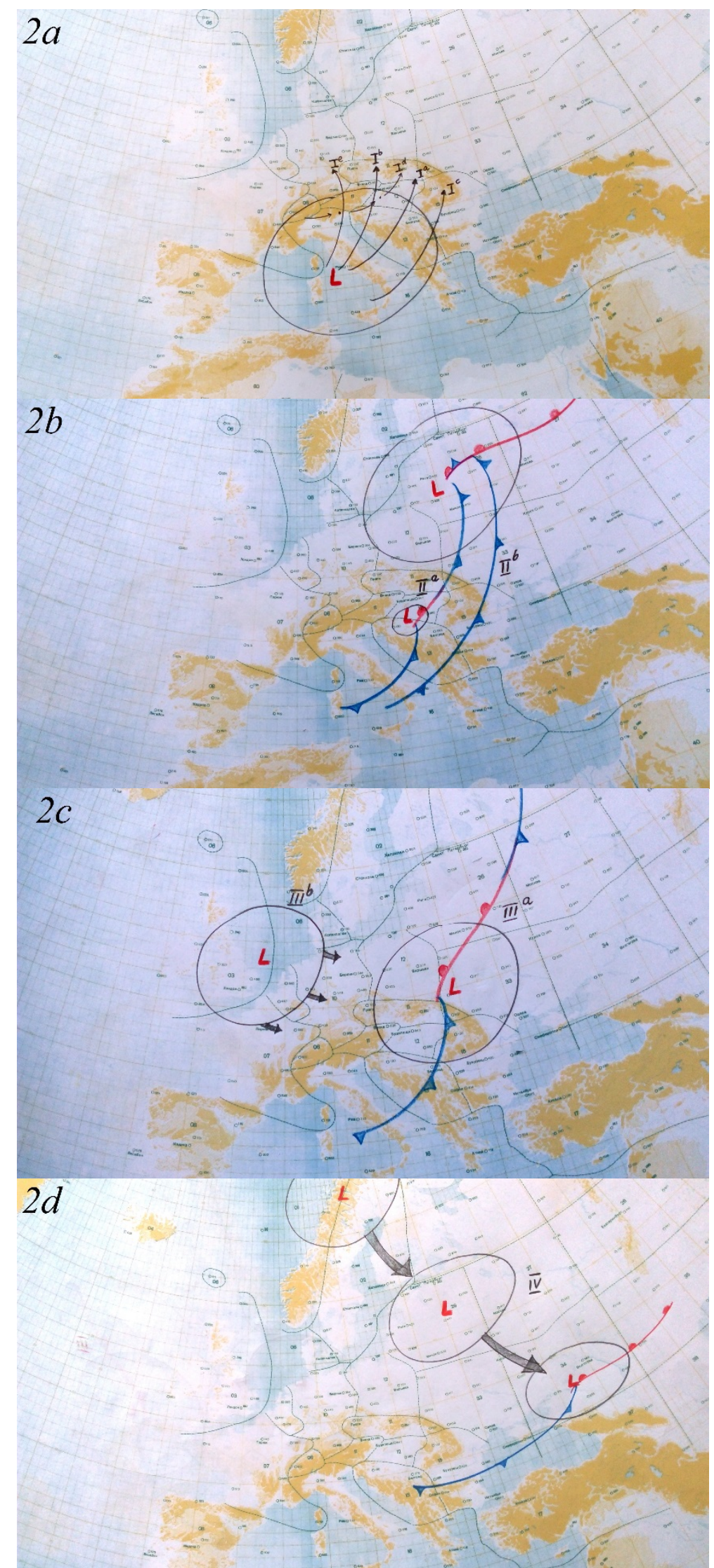

Fig. 2. Schematic chart of foehn: a) type I, b) type II, c) type III, and d) type IV.

In Figs. $3 a$ and $3 b$ a typical foehn class Ia is presented, on February 11 and 12, 1983. At the $500 \mathrm{hPa}$ chart on February 11, 1983, at 00 UTC (fig. $3 a$ ) it is 
seen, that the Balkan Peninsula is situated in front of a sharp trough with an axe over West Europe and the Iberian Peninsula, and in the upper-levels, the cyclone is over France. The pressure gradient is large. At the $850 \mathrm{hPa}$ chart, the transport of air masses is from S-SW, and it is seen that the entire Balkan Peninsula is in a warm air mass, with a temperature from 5 to $10{ }^{\circ} \mathrm{C}$. From the surface chart it can be seen that the cyclone over the Central Mediterranean is deep with pressure in its centre reaching $995 \mathrm{hPa}$. At the $500 \mathrm{hPa}$ chart at $12 \mathrm{UTC}$ on February 11, the cyclone moves south of France and deepens. The air masses transportation over the Balkans intensifies, and the warm air advection continues. From the surface chart (not shown) it is seen, that the cyclone moves N-NE through Central Italy and deepens over the Adriatic Sea with pressure in its centre reaching $990 \mathrm{hPa}$. a Mediterranean cyclone is clearly seen from the satellite images (Fig. 4), formed on February 11 over the Adriatic Sea. In Sofia, at 18 UTC, a S wind is registered with a wind gust of $18-22 \mathrm{~m} / \mathrm{s}$. During the evening, the temperature is $11.2{ }^{\circ} \mathrm{C}$, the relative humidity $56 \%$, and the pressure is $931.9 \mathrm{hPa}$. In Fig. $3 \mathrm{~b}$ are presented the synoptic conditions at 00 UTC on February 12, 1983 are presented. On February 12, at $500 \mathrm{hPa}$, the Balkan Peninsula remains in the front part of the trough, and the cyclone in the upper-levels is centered over South France. There is a large pressure gradient and a strong SW warm air advection aloft. At $850 \mathrm{hPa}$, a large part of the Balkans is still in a warm air mass, but with the withdrawal of the surface vortex towards Ukraine, cold air is advecting from NW to the peninsula. At the surface, the Mediterranean cyclone passes through Hungary, next towards Ukraine, and it is gradually filling up. In Sofia, a strong foehn, with wind gust ranging from 19 to $25 \mathrm{~m} / \mathrm{s}$, is recorded during the night of 11 and the afternoon of February 12. In the morning of February 12 , the temperature is $7.4{ }^{\circ} \mathrm{C}$ and the relative humidity is $54 \%$. 

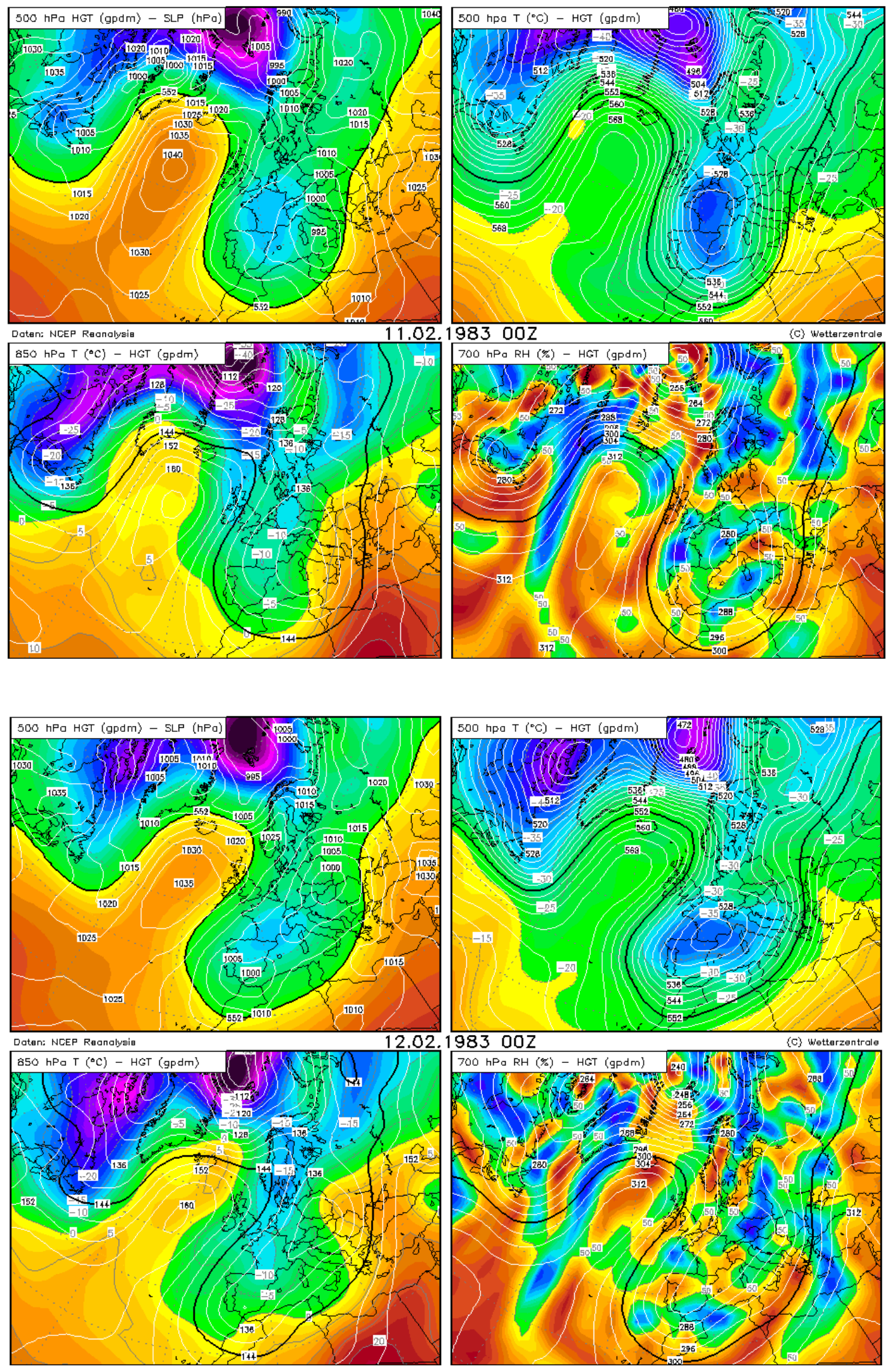

Fig. 3. Upper left panel - chart of surface pressure (with isolines) and geopotential height (in colors), upper right panel - chart $500 \mathrm{hPa}$ (with isolines), lower left panel - chart $850 \mathrm{hPa}$, lower right panel - chart $700 \mathrm{hPa}$ for the synoptic conditions on: a) February 11, 1983, at 00 UTC and b) February 12, 1983, at 00 UTC. 


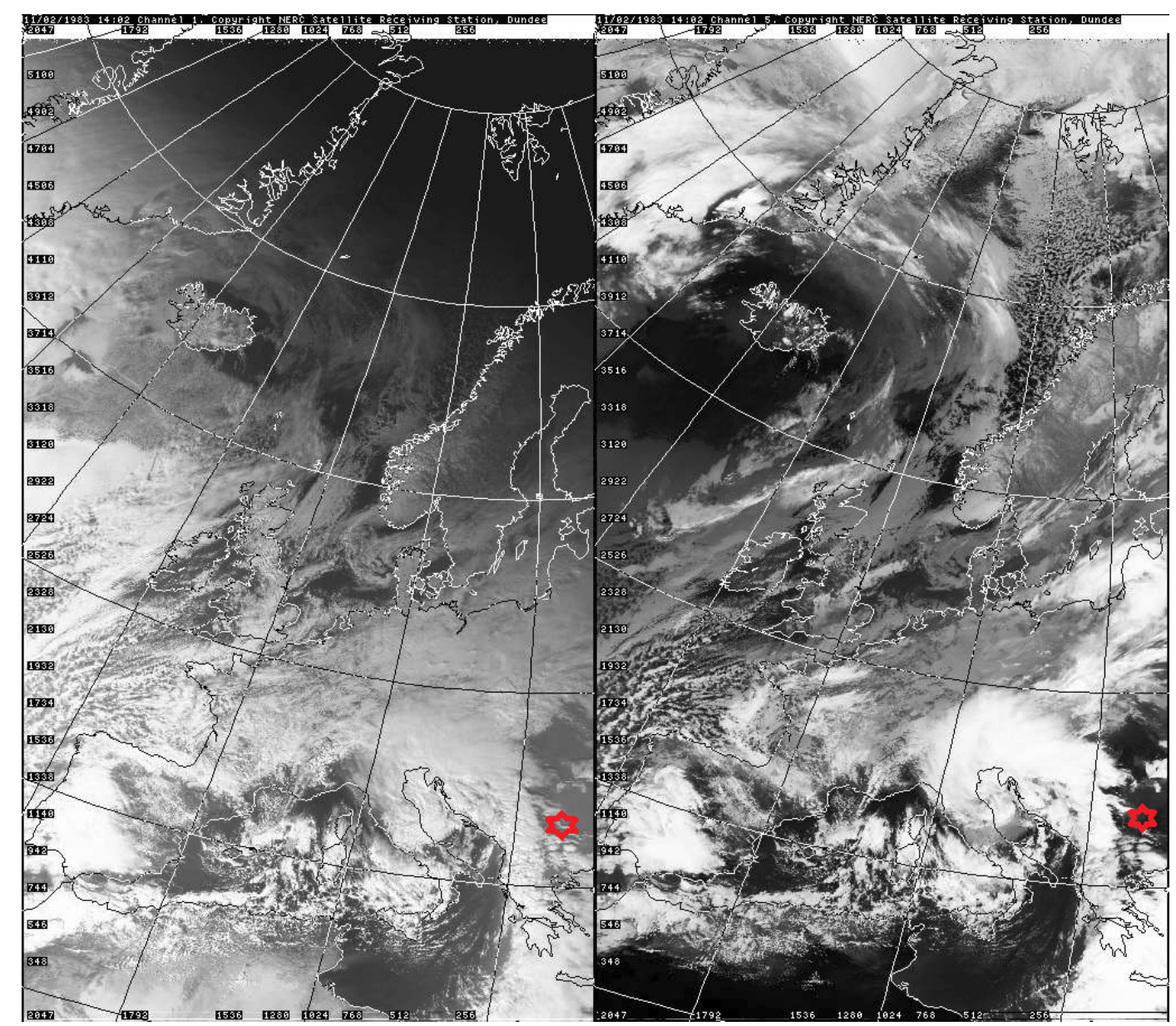

Fig.4. Satellite image in VIS (left panel) and IR (right panel) channels at 14 UTC on February 11, 1983.

\subsubsection{Foehn type II, III and IV}

Type II foehn is observed in 54 cases. In Fig. 2b, a schematic chart of foehn synoptic conditions of classes IIa and IIb are presented. These synoptic conditions are related to the evolution of a cyclone in the Baltic area. Class IIa is associated with cyclogenesis over Hungary during the cold front passage. Class $\mathrm{IIb}$ is ahead of the cold front passaging over the western part of the Balkan Peninsula. Foehn synoptic conditions of class IIb are observed in 19 cases.

Type III foehn is observed in 45 cases. In Fig. 2c, a schematic chart of foehn classes IIIa and IIIb are shown. Foehn class IIIa results from a cyclone in the North Sea, that moves over Central Europe. Class IIIb happens when the cyclone remains blocked over the British Isles and the North Sea. Foehn synoptic conditions of class IIIb are observed in 4 cases.

Type IV foehn is observed in 7 cases. In Fig. $2 d$, foehn type IV is shown. It is caused by a cyclone over the Scandinavian Peninsula, moving through the 
Baltic area towards the southern part of European Russia. These are the socalled "diving" cyclones.

Using the quantitative criteria of Hristov and Tanev (1970), 298 days with foehn are identified for the period 1975-2014. They resulted from 220 synoptic cases of which: 1) $114(52 \%)$ are type I, 2) 54 (25\%) are type II, 3) $45(20 \%)$ are type III, and 4) $7(3 \%)$ are type IV. Type I is divided into 5 classes: 1) Ia with $54,2)$ Ib with 13, 3) Ic with 15, 4) Id with 26, and 5) Ie with 6 cases. Type II has two classes: 1) IIa with 35 cases and 2) IIb with 19 cases. Foehn type III comprises two classes: 1) IIIa with 41 and 2) IIIb with 4 cases. Synoptic conditions of type IV are observed in 7 cases.

\subsection{Foehn climatology in Sofia for the period 1975-2014}

Fig. 5 depicts the number of days with foehn in Sofia per year. It is seen that the year with maximum days (18) with foehn is 1978. Only one day with foehn is registered in 2005 and 2012. Table 1 presents the average annual number of days with foehn in Sofia, which is 8.9, 8.1, 8.3, and 4.5 for the periods 19751984, 1985-1994, 1995-2004, and 2005-2014, respectively. For the period 1955-1964, Hristov and Tanev (1970) report 7 foehn days. After 2004, there is a tendency for decreasing of the number of days with foehn per year. The study of Marinova et al. (2005) demonstrates that the path I of the Mediterranean cyclones over Hungary is not typical any more. This is probably the reason for the decreasing of the mean annual number of days with foehn in Sofia after 2004. In Fig. 6, the number of days with foehn per month is shown. It is clearly seen, that the month with the largest number of days is March (56), followed by April (46), February (43), December (32), and November (29). The least frequent is the foehn in June (4). During the 40-year-long period, the longest foehn lasted from February 24 to March 2, 1989 (total -7 days). There are 3 cases with 4-day foehn, namely: 1) February 26 to March 1, 1990, 2) February 24 to 27, 1995, and 3) April 9 to 12, 1998. The number of cases with foehn persisting 72 hours are 10. Totally for the period 1975-2014, the most frequent foehn cases (47) lasted 2 days. In Fig. 7, the distribution of foehn cases with 2 days duration is presented. $25 \%$ and $23 \%$ of the foehn cases with 2 days duration occurred in March and April. For the 40-year-long period, the most persistent foehn, 44 hours, is type IIIa, which occurred in April 9-12, 1978. The foehn events with highest wind gust are types I and II. 


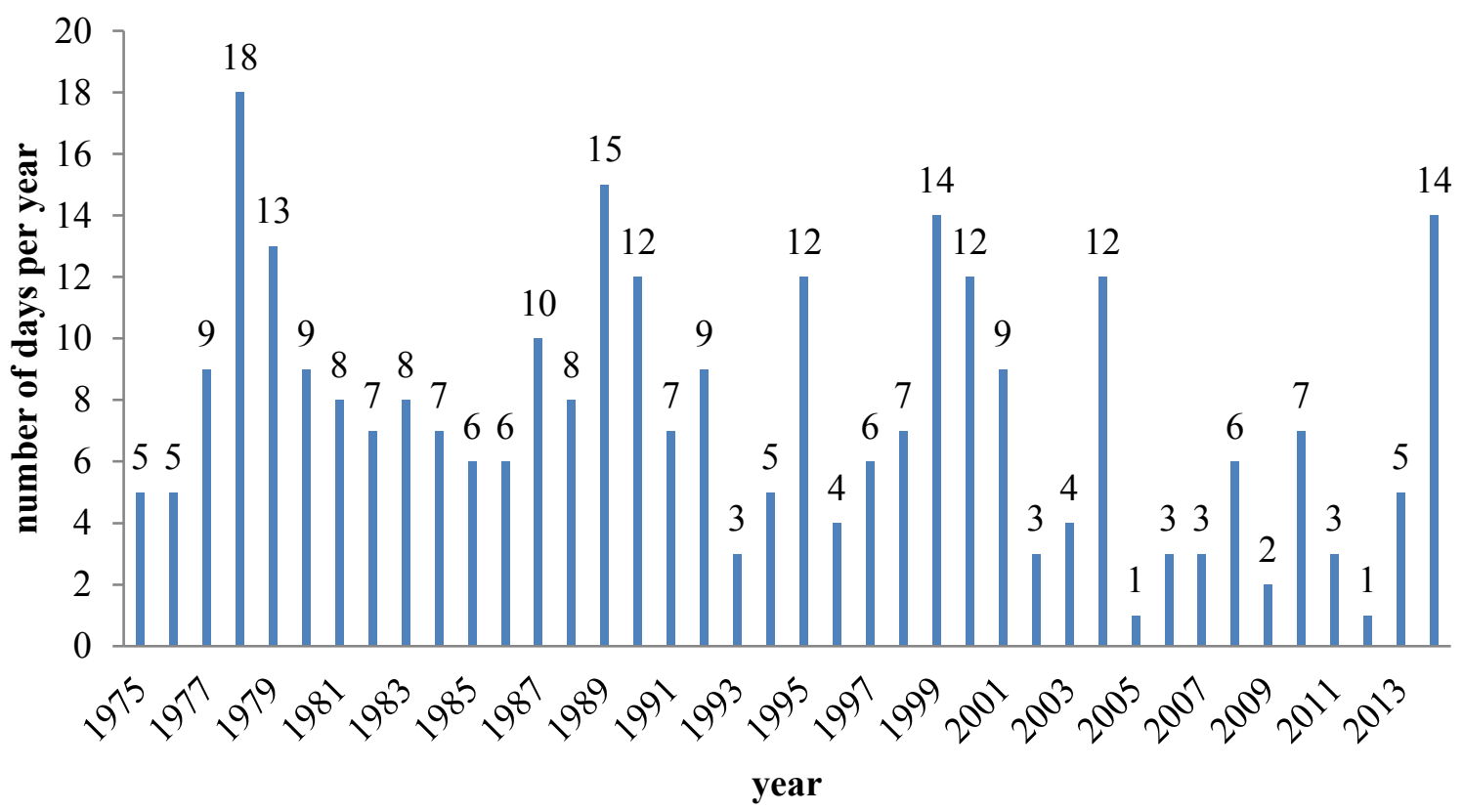

Fig. 5. Mean annual number of days with foehn in Sofia for the period 1975-2014.

Table 1. Number of foehn cases by type in Sofia during the period 1975-2014

\begin{tabular}{lcccccccccc}
\hline \hline Type & Ia & Ib & Ic & Id & Ie & IIa & IIb & IIIa & IIIb & IV \\
\hline \hline Number & 50 & 12 & 11 & 24 & 6 & 33 & 15 & 40 & 4 & 6 \\
\hline
\end{tabular}

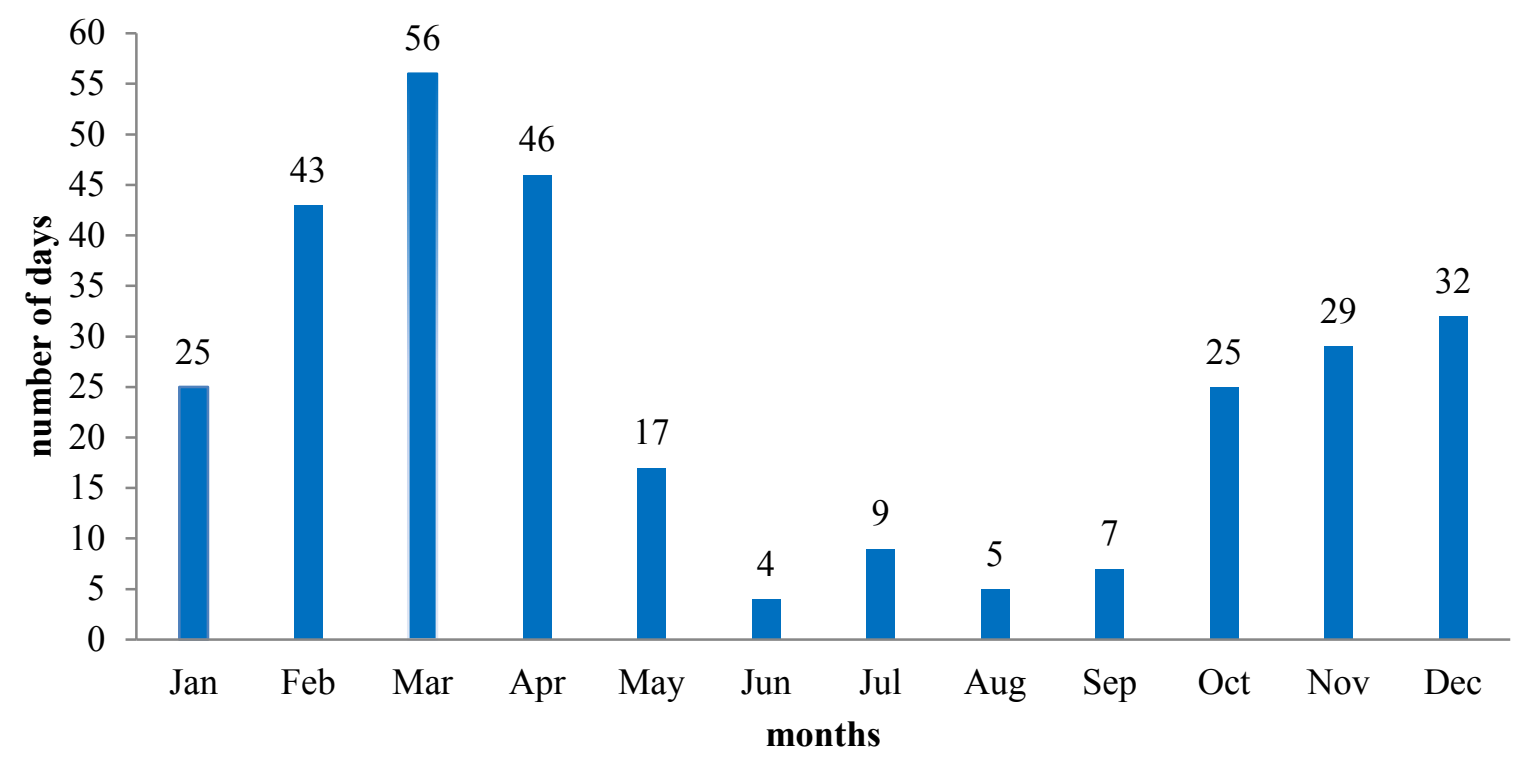

Fig. 6. Number of days with foehn in Sofia per month for the period 1975-2014. 


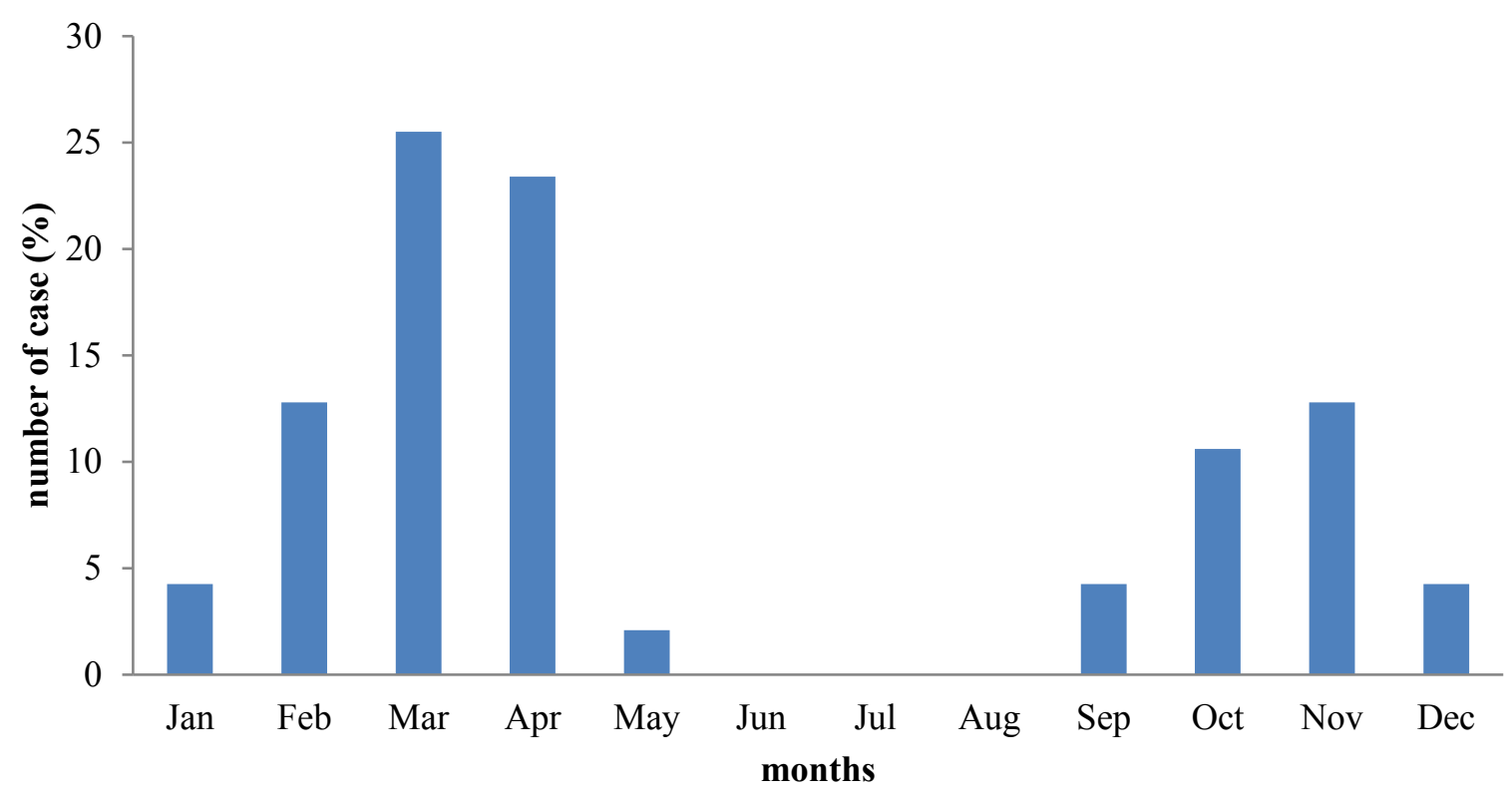

Fig. 7. Fractional monthly distribution of foehn cases with 2 days duration for the period 1975-2014.

\subsection{The foehn as a severe weather event}

As it can be seen from Fig. 8 , in $26 \%$ of the foehn days, the wind gust is less than $14 \mathrm{~m} / \mathrm{s}$, i.e., the foehn is not classified as a severe weather event according to the criteria used in Bulgaria. In 52\% of the days, the wind gust is from 14 to $19 \mathrm{~m} / \mathrm{s}$, and this corresponds to code "yellow" of the severe weather criteria of Meteoalarm in Bulgaria. In $21 \%$ of the days, the wind gust is $20-29 \mathrm{~m} / \mathrm{s}$ corresponding to code "orange", and in $1 \%$ of the days the wind gust is over $30 \mathrm{~m} / \mathrm{s}$, i.e., the alarm code is "red". For the 40 -year-long period, the number of cases with stormy wind over $30 \mathrm{~m} / \mathrm{s}$ are only 4, i.e., on average once per decade, the foehn is stormy in Sofia. The highest wind gust was registered in April 1975, with $32 \mathrm{~m} / \mathrm{s}$, and the weakest, with $5 \mathrm{~m} / \mathrm{s}$ on March 23, 2006. Table 2 presents the maximum wind gust per decade (1975-2014), and it is in the range 30$32 \mathrm{~m} / \mathrm{s}$ up to 2004. For the last decade (2005-2014), the maximum wind gust is $22 \mathrm{~m} / \mathrm{s}$. For the period 1955-1964, investigated by Hristov and Tanev (1970), the maximum registered wind gust during foehn in Sofia is $35-37 \mathrm{~m} / \mathrm{s}$. 


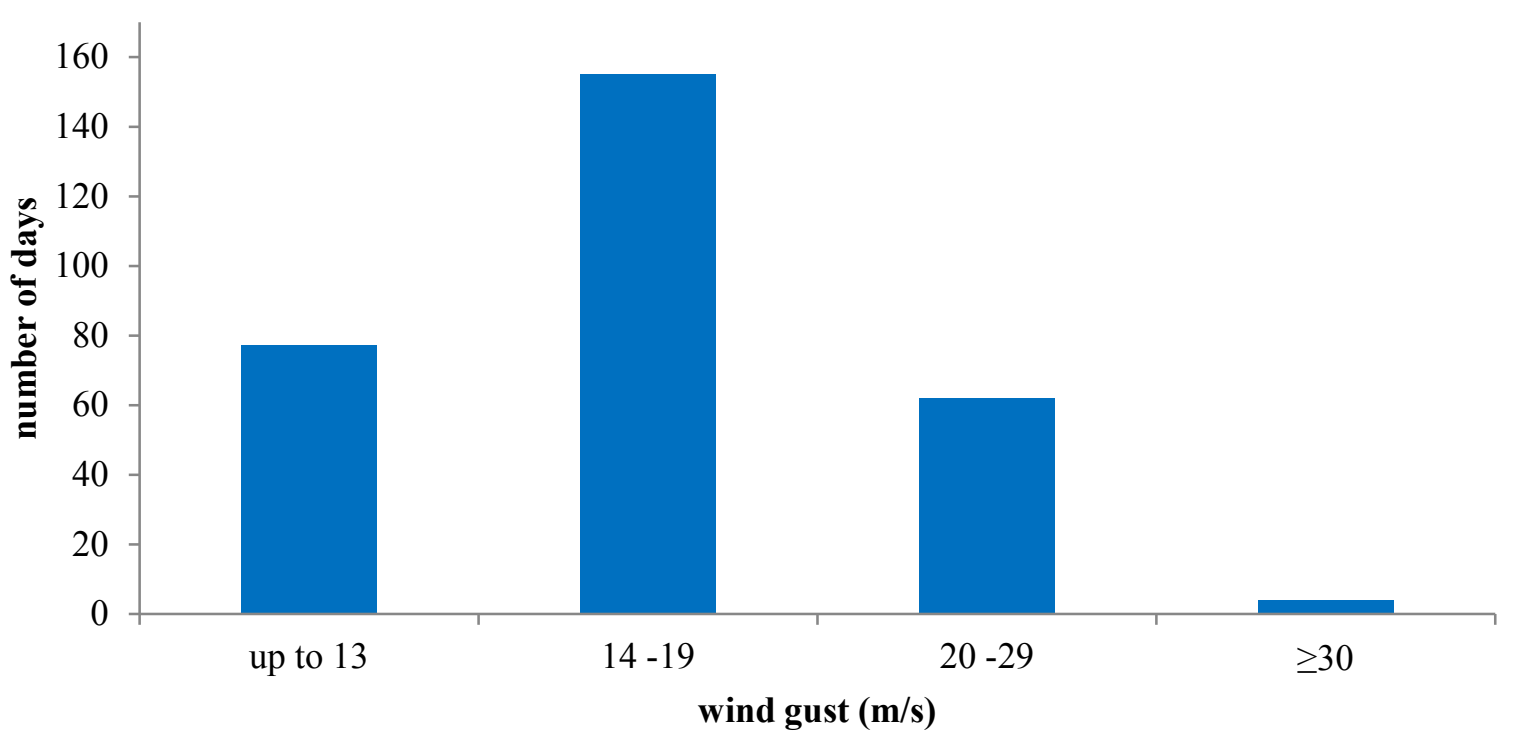

Fig. 8. Number of foehn days with wind speed: 1) up to $13 \mathrm{~m} / \mathrm{s}, 2) \% 14-19 \mathrm{~m} / \mathrm{s}$, 3) $20-29 \mathrm{~m} / \mathrm{s}$, and 4) over $30 \mathrm{~m} / \mathrm{s}$ for the 40 -year-long period.

Table 2. Number of foehn days per decade per year, and maximum wind gust per decade

\begin{tabular}{cccc}
\hline \hline Period & Number of days & Average number of days per year & Maximum wind gust (m/s) \\
\hline \hline $1975-1984$ & 89 & 8.9 & 32 \\
$1985-1994$ & 81 & 8.1 & 30 \\
$1995-2004$ & 83 & 8.3 & 30 \\
$2005-2014$ & 45 & 4.5 & 22 \\
\hline
\end{tabular}

In addition, the mean sea level pressure (msl), registered at 12 UTC in Sofia for the foehn days, is used to make a quantitative evaluation of the pressure for the 4 classification types. Fig. 9 presents the number of days with pressure in $5 \mathrm{hPa}$ bins for each classification type. It is clearly seen, that for type IV the msl pressure peak is at $1020 \mathrm{hPa}$, which is linked to the position of the low pressure system over the Baltic region (see Fig. 2d). Classification type I has an msl pressure peak at $1005 \mathrm{hPa}$. This is expected result and is linked to the Mediterranean cyclone trajectory, which influences the circulation over the Balkan Peninsula (Fig. 2a). For types II and III, the peak is at $1010 \mathrm{hPa}$ with a cyclone positioned mostly to the northwest of Bulgaria. 


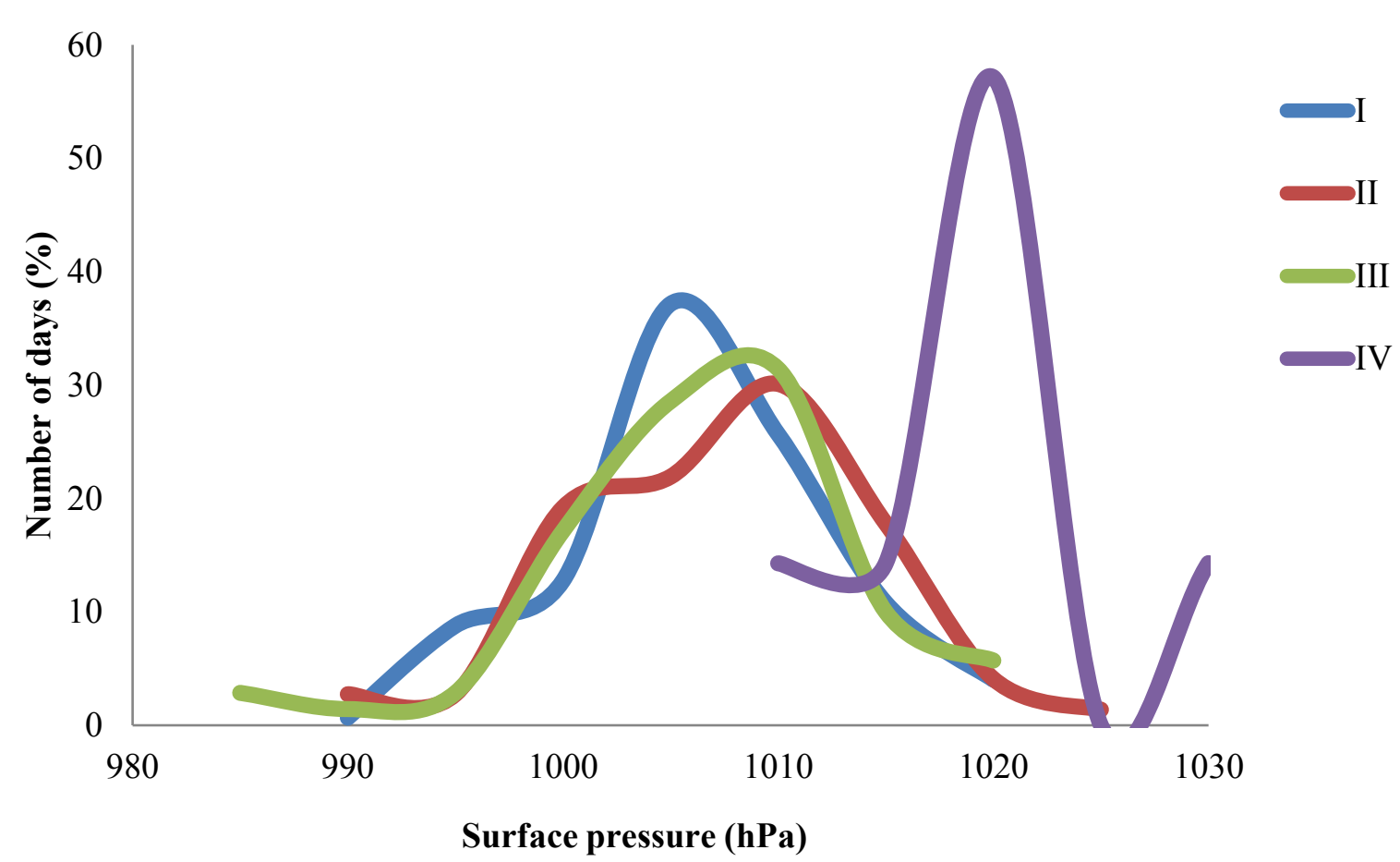

Fig. 9. Mean sea level pressure in Sofia for the classification types I (blue line), II (red line), III (green line), and IV (purple line). The number of days is given in percentage to take into account the different sample sizes of the classification types.

\section{Conclusion}

The work presents a classification of the synoptic conditions leading to a foehn in Sofia for the 40-year-long period 1975-2014. In this period, there were 298 days with foehn in Sofia, which resulted from 220 synoptic events from which: 1) $114(52 \%)$ are type I, 2) 54 (25\%) are type II, 3) 45 (20\%) are type III, and 4) 7 (3\%) are type IV. Type I is divided into 5 classes: 1) Ia with 54 cases, 2) Ib with 13,3) Ic with 15,4) Id with 26, and 5) Ie with 6 cases. Type II has two classes: 1) IIa with 35 cases and 2) IIb with 19 cases. Foehn type III comprises two classes: 1) IIIa with 41 and 2) IIIb with 4 cases. Synoptic conditions of type IV are observed in 7 cases. The average annual number of days with foehn in Sofia is 8.9, 8.1, 8.3, and 4.5 for 1975-1984, 1985-1994, 1995-2004, and 2005-2014, respectively. After 2004, a decrease of the average annual number of days with foehn is found and the lowest maximum wind gust is registered.

During the 40-year-long period, the longest foehn lasted from February 24 to March 2, 1989 (7 days in total). There are 3 foehn cases with duration of 4 days each. Cases with 72 hours duration are 10. For the period 1975-2014, the most frequent foehn is with 2 days duration (47 cases). The months with the largest number of foehn cases is March (56) followed by April (46), and February (43). In addition, a foehn climatology for Sofia is made and the foehn 
is classified as a severe weather event by wind gust. In $52 \%$ of the foehn days, the wind gust is 14-19 $\mathrm{m} / \mathrm{s}$, corresponding to code "yellow" of the severe weather criteria of Meteoalarm in Bulgaria. In $21 \%$ of the days, the wind gust is $20-29 \mathrm{~m} / \mathrm{s}$ (Meteoalarm code "orange"), and only in $1 \%$ of the days (4 cases in total), the wind gust exceeds $30 \mathrm{~m} / \mathrm{s}$ (Meteoalarm code "red"). The work will continue with evaluation of the foehn in the ERA5 reanalysis.

Acknowledgments: We are very grateful to Mrs. Mariana Popova from the National Institute of Meteorology and Hydrology for her contribution in editing the English version of the manuscript.

\section{References}

Blagoev, H., 1961: Patishta na Sredizemnomorskite Tsikloni,. Hydrol. Meteorol. 1, 43-51. (In Bulgarian)

van Bebber, $W$., 1891: Die zugstrassen der barometrischen minima nach den bahnenkarten der deutschen seewarte für den zeitraum 1875-1890. Meteor. Zeitschr. 8, 361-366. (In German)

Bocheva, L., Georgiev, Ch., and Simeonov, P., 2007: Aclimatic study of severe storms over bulgaria produced by mediterranean cyclones in 1990-2001 period. Atmos. Res. 83, 284-293.

https://doi.org/10.1016/j.atmosres.2005.10.018

Gutermann, T., Durr, B., Richner, H., and Bader, S., 2012: Fohnklimatologie Altdorf: die lange reihe (1864-2008) und ihre weiterf "uhrung, vergleich mit anderen stationen. (In German) https://www.research-collection.ethz.ch/bitstream/handle/20.500.11850/60511/eth-6318-01.pdf

Hristov, P. and Tanev, A., 1970: The climate of Sofia. Nauka i izkustvo. Sofia.

Jansa, A., Genoves, A., Picornell, M., Campins, J., Riosalido, R., and Carretero, O., 2001: Western Mediterranean cyclones and heavy rain. part 2. Stat. Approach Meteorol. Appl. 8, 43-56. https://doi.org/10.1017/S1350482701001049

Marinova, T., Bocheva, L., and Sharov, V., 2005: On some climatic changes in the circulation over the mediterranean area. Idöjárás 109, 55-67.

Martinov, M., 1967: Some peculiarities of cyclogenesis in the region of the Mediterranean sea and the Balkan Peninsula. Hydrol. Meteorol. 6, 7-21. (In Bulgarian)

Martinov, M., 1983: Synoptical and statistical processing of historical data for Mediterranean depression. WMO, PSMP Report Series 3, 121-144.

Peiter, E., 1975: Handbook for forecasters in the Mediterranean. Technical Report 344, Environmental Prediction Research Facility, Naval Postgraduate School, Monterey, California.

Pisarski, A., 1955a: Sredizemnomorskite Tskiloni i tyahnoto vilyanie na vremeto v Bulgaria, part I. Hidrologia i Meteorologia. 5, 33-50. (In Bulgarian)

Pisarski, A., 1955b: Sredizemnomorskite Tskiloni i tyahnoto vilyanie na vremeto v Bulgaria, part II. Hidrologia i Meteorologia 6, 3-15. (In Bulgarian)

Popova, T., Runcanu, T., Tanczer, T., and Sharov, V., 1975: Sredizemnomorskie tsiklony v pole oblachnosti. Gidrometeoizdat. Leningrad. (In Russian)

Radinovic, D., 1987: Mediterranean cyclones and their influence on the weather and climate. WMO, PSMP Report Series 24. 131.

Richner, H. and H"achler, P., 2013: Understanding and forecasting alpine foehn. In: Mountain Weather Research and Forecasting, Springer.. 219-260. https://doi.org/10.1007/978-94-007-4098-3_4

Stanchev, K., 1954: Yuzhnite Tsikloni, dvizhenieto im prez Balkanskiya poluostrov i vliyanieto im nad vremeto v Bulgaria. Hidrologia i Meteorologia 5, 19-39. (In Bulgarian)

Willemse, S. and Furger, M., 2016: From weather observations to atmospheric and climate sciences in Switzerland. vdf Hochschulverlag AG an der ETH Zürich. http://e-collection.library.ethz.ch/ 